\title{
Dynamic and Probabilistic Analysis of Shear Deformable Pipeline Resting on Two Parameter Foundation
}

\author{
Meriem Seguini ${ }^{1 *}$, Djamel Nedjar ${ }^{1}$ \\ ${ }^{1}$ Department of Civil Engineering, Faculty of Architecture and Civil Engineering, Laboratory of Mechanic of Structures and \\ Stability of Constructions LM2SC, University of Sciences and Technology of Oran Mohamed Boudiaf, Bp 1505 Elmenouar Oran, \\ Algeria \\ *Corresponding author, e-mail: meriem.seguini@univ-usto.dz
}

Received: 02 September 2019, Accepted: 27 January 2020, Published online: 23 March 2020

\begin{abstract}
The nonlinear dynamic deterministic and probabilistic analysis of pipeline undergoing large deflections and resting on WinklerPasternak foundation have been done. Dynamic analogues of Euler Bernoulli and Timoshenko Von-Kármán type beam equations are used. The stochastic finite element approach based on the Vanmarcke method combined to Monte Carlo simulations has been used to solve the governing nonlinear equations of soil-pipe interaction. The influence of different parameters of random soil is has been analyzed and the obtained results are compared with those obtained from the literature. It is concluded from the present work that the spatial variability of the soil properties has a great impact on the seismic response of the pipe and the developed model which is based on the accurate method is efficient to determine the real response of the safe and economic pipeline.
\end{abstract}

Keywords

nonlinear dynamic analysis, Euler Bernoulli beam, Timoshenko beam, shear deformation, spatial variability, Monte Carlo simulation, Winkler-Pasternack foundation

\section{Introduction}

In recent years, new and creative solutions have been developed for pipeline design due to their importance in transporting energy and water, thus calculation methods have been improved to perform and design a safe and economical pipeline which has often modeled as a beam. The behavior of the beam has received a great attention of researchers due to its wide application in engineering, where the beam resting on different types of foundation as Winkler, Kerr, Pasternack and Vlassov and subjected to static loading has been studied extensively [1-6]. Moreover, several research studies on linear and nonlinear dynamic analyses of Euler and Timoshenko beam resting on foundation have been performed [7-17], where the soil-interaction phenomenon effect on the pipe response has been taken into account [9-11]. In fact, Hosseini Kordkheili et al. [12] used the Lagrangian formulation [13] for the static and dynamic analysis of pipe and the 3D flexible riser. In addition, constitutive models of nonlinear beam on viscoelastic soil [14-18] have been suggested by different researchers to analyze the dynamic behavior of the beam. In the work due to Sapountzakis and Kampitisis [18] the soil was simulated as a nonlinear viscoelastic foundation and the Timoshenko theory has been used to study the nonlinear dynamic response of the shear deformable beam.

Currently, taking into account the spatial variability of soil's parameters become an essential aspect of geotechnical engineering. In fact, recent developments on the static analysis beam are documented in the article by Grigoriu et al. [19] and Griffiths et al. [20]. Moreover, an art of view of probabilistic soil modeling has been established [21] and various constitutive models of soil-structure interaction based on the probabilistic approach have been developed [22-24]. Elachachi et al. [22, 23] used the theory of Vanmarcke in order to quantify the effect of different random parameters of soil on the pipe response, by taking into account two different models of soil (Winkler and the modified Vlassov model). In this context Kazi Tani et al. [25] presented stochastic finite difference method to study the linear response of pipeline resting on elastic perfectly plastic soil. Moreover, Seguini and Nedjar [26-29] made an important study and employed the finite element method based on the Von Kármán assumption, combined to the theory of the local average to assess the spatial variability 
effects and shear deformation on the large deflection of pipe and deep beam resting on linear and nonlinear random soil where the coefficient of subgrade reaction ksoil is considered variable (see Section 3).

However, research efforts devoted to dynamic soil-structure interaction taking into consideration the random soil properties have been also very limited [23, 30-34]. Nedjar et al. [30, 31] and Elachachi et al. [23] analyzed the dynamic deflection of the pipe resting on random soil by combining the theory of the local average of Vanmarcke to the Newmark formulations.

The present work focuses on the nonlinear dynamic response of pipeline in a spatially varied soil medium $\left(\mathrm{k}_{\text {soil }}=\right.$ variable $)$ where a computer program has been written and representative examples have been studied. This task led to the improvement of an existing nonlinear model for pipeline [26] based on the theory of Euler and Timoshenko beam and the developed new models are subjected to the effect of propagation of seismic soil motion. The geometric nonlinear response of the beam is obtained by using the Von Kármán formulation based on the assumption of large deflection and moderate rotations of the beam. The Winkler-Pasternak soil was simulated as nonlinear foundation. The noticeable in the present approach is that the dynamic analysis combined to the Vanmarcke method is an important part on the determination of the real behavior of the pipe.

\section{Governing equations}

\subsection{Finite element formulation}

The relationship between the motion of the structure and the soil pressure is used to represent the soil-structure interaction system. The Kelvin-Voigt model is used to model the soil where the interface element is represented by a spring and a dashpot which are connected in parallel (Fig. 1). In fact, the governing equation of the system is defined by the following expression and it is solved for each time history of the Loma Prieta earthquake where the Newmark's method is used to carry out the numerical integration:

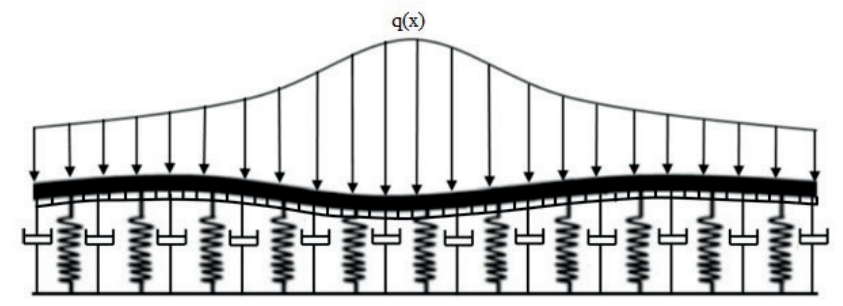

Fig. 1 Model of the pipe resting on Winkler-Pasternack foundation, subjected to a distributed load and to the Loma earthquake
$\left[M_{p}\right]\{\ddot{U}\}+\left[C_{p}+C_{s}\right]\{\dot{U}\}+\left[K_{p}+K_{s}\right]\{U\}=$

$\left[C_{s}\right]\left\{\dot{u}_{s}\right\}+\left[K_{s}\right]\left\{u_{s}\right\}$.

With

$\left\{U=u_{s}+u\right\}$.

Noting that $M_{p}$ is the mass matrix of the structure, $K_{p}$ and $K_{s}$ are the stiffness matrices of the structure and the soil respectively. $C_{p}$ and $C_{s}$ are the damping matrices of the structure and the soil respectively.

$u, \dot{u}, \ddot{u}$ denote the vectors of the relative displacement, relative velocity and relative acceleration, respectively. Furthermore $u_{s}, \dot{u}_{s}, \ddot{u}_{s}$ denote the vectors of ground displacement, ground velocity and ground acceleration respectively (Fig. 2).

\subsubsection{Euler-Bernoulli theory}

The strain energy of the pipe (beam) is defined as [27, 35] as follow (Eq. (3)):

$\Psi_{1}=\frac{1}{2} \int_{0}^{l e}\left\{E^{e} A^{e}\left[\frac{d u_{0}}{d x}+\frac{1}{2}\left(\frac{d w_{0}}{d x}\right)^{2}\right]+E^{e} I^{e}\left(\frac{d^{2} w_{0}}{d x^{2}}\right)^{2}\right\} d x$

$w_{0}(x)=[N]^{t} \cdot\left\{u^{e}\right\}$ where $N$ is the vector composed of interpolation functions of Hermite type and $\left\{u^{e}\right\}$ is the vector of displacement of pipe element e. $E_{e}$ and $A_{e}$ are respectively the Yong modulus and the moment of inertia of the pipe element. By neglecting the derivative of axial displacement $\left(d u_{0} / d x\right)$, the equation of beam strain energy is determined as follows [26]:

$$
\begin{aligned}
\Psi_{1} & =\frac{1}{2} \int_{0}^{l e}\left\{E^{e} A^{e}\left[\frac{1}{2}\left(\frac{d w_{0}}{d x}\right)^{2}\right]+E^{e} I^{e}\left(\frac{d^{2} w_{0}}{d x^{2}}\right)^{2}\right\} d x, \\
\Psi_{1} & =\frac{1}{2}\left\{u^{e}\right\}^{t}\left\{\left[\frac{1}{2} E^{e} A^{e} \int_{0}^{l e}\left(\frac{d w_{0}}{d x}\right)^{2}\left(\frac{d N}{d x}\right)\left(\frac{d N}{d x}\right)^{t} d x\right]\right. \\
& \left.+\left[E^{e} I^{e} \int_{0}^{l e}\left(\frac{d^{2} N}{d x^{2}}\right)\left(\frac{d^{2} N}{d x^{2}}\right)^{t} d x\right]\right\}\left\{u^{e}\right\},
\end{aligned}
$$

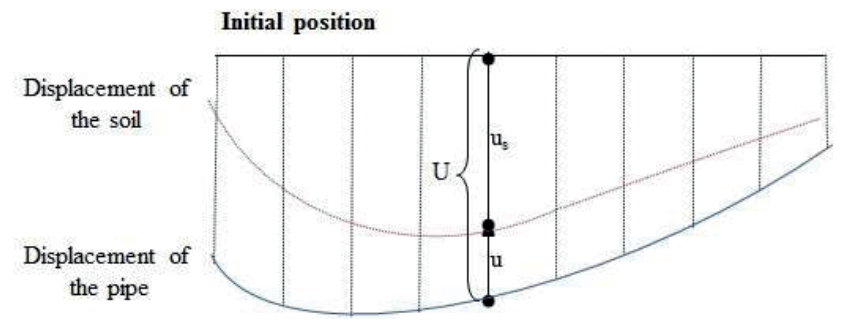

Fig. 2 Behavior of the soil-pipe system 
$\Psi_{1}=\frac{1}{2}\left\{u^{e}\right\}^{t}\left[K_{p n L}^{e}\left\{u^{e}\right\}+K_{p l}^{e}\right]\left\{u^{e}\right\}$

where $\left\{u^{e}\right\}=\left\{w_{1} \theta_{1} w_{2} \theta_{2}\right\}^{\prime} . E^{e} A^{e}$ and $E^{e} T^{e}$ are the extension and flexural rigidity of beam element. $\left[K_{p n L}^{e}\right]$ and $\left[K_{p L}^{e}\right]$ are, respectively, the linear and geometric non-linear matrices of rigidity of the beam element.

The Kinetic energy of the beam is defined by taking into account the rotary inertia and the axial inertia effects and it can be expressed as:

$$
\begin{aligned}
\phi & =\frac{1}{2}\left\{\dot{u}^{e}\right\}^{t}\left\{\left[\frac{1}{2} \rho_{b} A^{e} \int_{0}^{l e}\left(\frac{d w_{0}}{d x}\right) N \cdot N^{t} d x\right]\right. \\
& \left.+\left[\rho_{b} I^{e} \int_{0}^{l e}\left(\frac{d N}{d x}\right)\left(\frac{d N}{d x}\right)^{t} d x\right]\right\}\left\{\dot{u}^{e}\right\}, \\
\phi & =\frac{1}{2}\left\{\dot{u}^{e}\right\}^{t}\left\{\left[\frac{1}{2} \rho_{b} A^{e} \frac{w_{2}-w_{1}}{l_{e}} \int_{0}^{l e} N \cdot N^{t} d x\right]\right. \\
& \left.+\left[\rho_{b} I^{e} \int_{0}^{l e}\left(\frac{d N}{d x}\right)\left(\frac{d N}{d x}\right)^{t} d x\right]\right\}\left\{\dot{u}^{e}\right\} .
\end{aligned}
$$

$\rho_{b}$ is the mass of the beam per unit volume.

$\phi=\frac{1}{2}\{\dot{u}\}^{t}\left[M_{n L}^{e}\{U\}+M_{l}^{e}\right]\{\dot{u}\}$

$M_{L}$ and $M_{n L}$ are respectively the linear and nonlinear masse matrices of the beam.

\subsubsection{Timoshenko theory}

The strain energy of the beam is determined as follows [28]:

$$
\begin{aligned}
\psi_{1} & =\frac{1}{2} \int_{0}^{l e}\left\{E A\left[\frac{1}{2}\left(\frac{\partial w_{0}}{\partial x}\right)^{2}\right]^{2}+K_{s b} G A\left(\frac{\partial w_{0}}{\partial x}+\varphi_{x}\right)^{2}\right. \\
& \left.+E I\left(\frac{\partial \varphi_{x}}{\partial x}\right)^{2}\right\} d x \\
\psi_{1}= & \frac{1}{2}\left\{u^{e}\right\}^{t}\left\{\left[\frac{1}{2} E A \int_{0}^{l e}\left(\frac{\partial w_{0}}{\partial x}\right)^{2}\left(\frac{\partial N}{\partial x}\right)\left(\frac{\partial N}{\partial x}\right)^{t} d x\right]\right. \\
& +\left[K_{s b} G A \int_{0}^{l e}\left(\frac{\partial w_{0}}{\partial x}+\left(\frac{\partial N}{\partial x}\right)\left(\frac{\partial N}{\partial x}\right)^{t}\right)^{2} d x\right] \\
& \left.+\left[E I \int_{0}^{l e}\left(\frac{\partial^{2} N}{\partial x^{2}}\right)\left(\frac{\partial^{2} N}{\partial x^{2}}\right)^{t} d x\right]\right\}\left\{u^{e}\right\} .
\end{aligned}
$$

$G$ is the shear modulus $G=E / 2(1+v)$, where $v$ is the Poisson ratio of the beam. The shear correction factor $K_{s b}$ is equal to $5 / 6$ [36]. The Kinetic energy of Timoshenko beam can be expressed as:

$$
\begin{aligned}
\phi & =\frac{1}{2}\{\dot{U}\}^{t}\left\{\left[\frac{1}{2} \rho_{b} A \int_{0}^{l e}\left(\frac{\partial w_{0}}{\partial x}\right) N N^{t} d x\right]\right. \\
& +\left[K_{s} G A \int_{0}^{l e} \frac{\partial w_{0}}{\partial x}+\left(\frac{\partial N}{\partial x}\right)\left(\frac{\partial N}{\partial x}\right)^{t} d x\right] \\
& \left.+\left[\rho_{b} I_{b} \int_{0}^{l e}\left(\frac{\partial N}{\partial x}\right)\left(\frac{\partial N}{\partial x}\right)^{t} d x\right]\right\}\{\dot{U}\},
\end{aligned}
$$

Where $\rho_{b}$ is the mass of the soil per unit volume.

\subsubsection{Linear and nonlinear soil}

The strain energy stored in the soil during the beam deformation is defined as follow:

$\Psi_{2}=\frac{1}{2} \int_{0}^{l e} p_{e}(x) \cdot w(x) d x$.

$p_{e}(x)$ is the Winkler and Pasternak reaction and it is defined as follows:

$p_{e}(x)=p_{w}(x)+p_{p}(x)$,

$p_{e}(x)=k_{w} \cdot \pi R_{\text {ext }} \cdot w(x)-k_{s} \cdot \pi R_{\text {ext }} \cdot \frac{d^{2} w}{d x^{2}}$,

where $k_{w}$ and $k_{s}$ are the coefficient of subgrade reaction of Winkler and Pasternak soil's respectively, $R_{e x t}$ is the radius of the pipe (beam).

For elastic nonlinear soil model, the coefficient $k_{w}$ for an element $e$ is [27]:

$\left\{\begin{array}{ll}p_{w}=k_{w} w_{e} & 0 \leq w_{e} \leq s_{u} \\ p_{w}=p_{u} & w_{e} \succ s_{u}\end{array}\right.$.

$S_{u}$ is the soil yield displacement, $w_{e}$ is the displacement of an element pipe e. $P_{u}$ is the ultimate subgrade reaction. However, the strain energy of the soil is expressed as:

$\Psi_{2}=\frac{1}{2}\{U\}^{t}\left[K_{s}\right]\{U\}$.

$\left[K_{\text {soil }}\right]$ is the matrix of rigidity of the soil. It is defined as follows [31-32]:

$\left[K_{s}\right]=\left[K_{w}\right]+\left[K_{p}\right]$

with 


$$
\begin{aligned}
& {\left[K_{w}\right]=\frac{k_{w} \pi R_{e x t} L}{420}\left[\begin{array}{cccc}
156 & 22 L & 54 & -13 L \\
22 L & 4 L^{2} & 13 L & -3 L^{2} \\
54 & 13 L & 156 & -22 L \\
-13 L & -3 L^{2} & -22 L & 4 L^{2}
\end{array}\right],} \\
& {\left[K_{P}\right]=\frac{k_{s} \pi R_{e x t}}{30 l_{e}}\left[\begin{array}{cccc}
36 & 3 l_{e} & -36 & 3 l_{e} \\
3 l_{e} & 4 l_{e}^{2} & -3 l_{e} & -l_{e}^{2} \\
-36 & -3 l_{e} & 36 & -3 l_{e} \\
3 l_{e} & -l_{e}^{2} & -3 l_{e} & 4 l_{e}^{2}
\end{array}\right] .}
\end{aligned}
$$

The Rayleigh's method is used to take into account the variation of the soil damping where $k_{\text {soil }}$ and $\rho_{\text {soil }}$ are variables. In fact, the damping element matrix is given by the following expression [31]:

$C_{s}^{e}=\alpha M_{s}^{e}+\beta K_{s}^{e}$.

\section{Spatial variability modeling via Monte Carlo simulations}

The stochastic finite element method is becoming firmly established as an important tool of probabilistic structural analysis. Working with uncertainty is therefore an essential aspect of geotechnical engineering. In this work a probabilistic approach based on the theory of local average of Vanmarcke [37] based on the Monte Carlo method has been used.

The coefficient of subgrade reaction random field is characterized by a lognormal distribution and has been simulated via local average subdivision method with a fixed mean $m_{k}$, a variance $\sigma_{k}^{2}$, and a spatial correlation length structure $\left(L_{c}, L_{c s}\right)$.

The mean and variance are constant throughout the entire soil field and give an average value of the coefficient of subgrade reaction of each zone of the soil where the summation of all these zones averages values is equal to the average $m_{k}$. The local average of the coefficient of subgrade reaction $k_{\text {soil }}$ is expressed as (Seguini and Nedjar [26]):

$$
E\left[k_{\text {soil }}\left(D_{i}\right)\right]=m_{k},
$$

and in each zone (i) of length $D_{i}$, the variance of $k_{\text {soil }}$ is given as follow (Seguini and Nedjar[26]):

$\operatorname{Var}\left[k_{\text {soil }}\left(D_{i}\right)\right]=\sigma_{k}^{2} \gamma\left(D_{i}\right)$,

where $k_{\text {soil }}=k_{w}=k_{s}$ and $\gamma\left(D_{i}\right)$ is the variance function which depends on the spatial correlation function $\rho(x)$ and determined by Vanmarcke [37] as:
$\gamma\left(D_{i}\right)=\frac{2}{D_{i}} \int_{0}^{D_{i}}\left(1-\frac{x}{D_{i}}\right) \rho(x) d x$

with $\rho(\tau)=1-\frac{|\tau|}{L_{c}}$ for $|\tau| \leq L_{c}$

by introducing Eq. (25) into Eq. (24), we obtain the variance function in a discrete formulation as follows (Seguini and Nedjar [26]):

$\gamma\left(D_{i}\right)=\left\{\begin{array}{lll}1-\frac{D_{i}}{3 L_{c}} & \text { if } & D_{i} \leq L_{c} \\ \frac{L_{c}}{D_{i}}\left(1-\frac{L_{c}}{3 D_{i}}\right) & \text { if } & D_{i} \succ L_{c}\end{array}\right.$.

To generate the random variable and compute the covariance matrix $C_{i j}$ of the coefficient of soil's subgrade reaction, the local average subdivision method developed by Fenton and Vanmarcke [38] has been used where each term of this matrix corresponds to the correlation between two zones $(i)$ and $(j)$ of length $D_{i}$ and $D_{j}$ respectively (Seguini and Nedjar [26]).

$$
\begin{aligned}
C_{i j}= & \operatorname{Cov}\left[k_{\text {soil }}\left(D_{i}\right), k_{\text {soil }}\left(D_{j}\right)\right], \\
C_{i j}= & \frac{\sigma_{k}^{2}}{2}\left\{(t-1)^{2} \gamma[(t-1) D]\right. \\
& \left.-2 t^{2} \gamma[t . D]+(t+1)^{2} \gamma[(t+1) D]\right\},
\end{aligned}
$$

where $t=|i-j|$ is the difference between two spatial zones $(i)$ and $(j)$ in absolute value with a same length $(D=D i=\mathrm{v} j)$.

In this study, a Matlab software has been used to introduce the deterministic and probabilistic properties of pipe and soil. The random soil is discretized in several zones, the lognormal distribution of random $k_{\text {soil }}$ is generated and the displacement vector of the linear system is determined where it is assumed that the nonlinear rigidity and mass matrices of the pipe and the soil are equal to zero. In the second step these last matrices are not equal to zero, the global stiffness matrix is calculated and the displacement vector of the nonlinear system is determined.

\section{Numerical study}

The behavior of a simply supported pipeline of length $L$, diameter $D$, thickness $e$, resting on nonlinear two-parameters foundation subjected to a distributed load Fig. 1 $(q=25 \mathrm{kN} / \mathrm{m})$ and to the Loma earthquake has been studied. For comparison reasons the properties of pipeline and soil are deduced from literature [26] and resumed in Table 1. 
Table 1 Deterministic and Probabilistic properties of the pipe and the soil [26]

\begin{tabular}{lcc}
\hline Item & Notation & Value \\
\hline Concrete pipe & & \\
\hline Diameter & $D_{\text {ext }}$ & $1 \mathrm{~m}$ \\
Length & $L_{p}$ & $62 \mathrm{~m}$ \\
Young modulus & $E_{c}$ & $3 \times 104 \mathrm{MPa}$ \\
Flexural rigidity & $E_{c} I_{c}$ & $869.45 \mathrm{MN} / \mathrm{m}^{2}$ \\
Poisson ratio & $v_{p}$ & 0.2 \\
Soft clay & & \\
\hline Young modulus & $E_{s}$ & $12.5 \mathrm{MPa}$ \\
Poisson ratio & $v_{s o i l}$ & 0.35 \\
Coefficient of Winkler soil's & $k_{w}$ & $3.067 \mathrm{kN} / \mathrm{m}^{3}$ \\
subgrade reaction & & \\
Coefficient of Pasternack soil's & $k_{s}$ & $800,1500 \mathrm{kN} / \mathrm{m}$ \\
subgrade reaction & & $6,12,24,60 \mathrm{~m}$ \\
Probabilistic properties & $L_{c}$ & $6,24 \mathrm{~m}$ \\
\hline Correlation length of Winkler soil & $L_{v}$ & \\
Correlation length of Pasternack soil & & \\
Coefficient of variation of soil & & \\
\hline & & \\
\hline
\end{tabular}

On the basis of the hypothesis and numerical procedures presented in the previous sections, a Matlab program has been written and representative example has been studied to demonstrate the efficiency of the developed model. However, a stochastic nonlinear numerical modeling based on to Monte Carlo simulations has been adopted in this work.

\subsection{Deterministic analysis}

Table 2 shows the difference between the maximum deflections predicted by the Loma earthquake in order to illustrate the importance of the seismic effect. From Table 2, it can be noted that the dynamic analysis allows us to obtain safe and reliable model and to prove that it is very important to consider the effect of the Loma Prieta earthquake.

Table 2 Maximum deflection of the nonlinear pipe $W_{\max }$ resting on Winkler foundation

\begin{tabular}{lcc}
\hline & With seismic effect & Without seismic effect \\
\hline$W_{\max }[\mathrm{m}]$ & $1.481 \times 10^{-4}$ & $7.98 \times 10^{-5}$ \\
\hline
\end{tabular}

In Table 3 the maximum values of the midpoint relative displacement are determined for all the cases of analysis according to both linear and nonlinear beam theory. The results reveal that the dynamic maximum deflections obtained by the nonlinear analysis are smaller than ones obtained by the linear analysis, because the pipe is stiffer by the nonlinear term generated by the large deflections.

It seen also that the maximum deflection decreases when the shear coefficient of the pipe (Timoshenko theory) is taken into account. The maximum deflection of the pipe resting on Pasternak foundation is greater than the maximum deflection of the beam resting on Winkler foundation which proved the accuracy of the proposed model and the influence of the nonlinear Winkler-Pasternack (shear modulus) on the response of the pipe. In fact for more details, the illustrated curves of the Fig. 3 shows the time histories of the deflection of the pipe for various models of the soil.

In Table 4 the maximum values of the displacement of the pipe taking into account or ignoring the damping and the shear effect, are presented. It is clearly seen that the

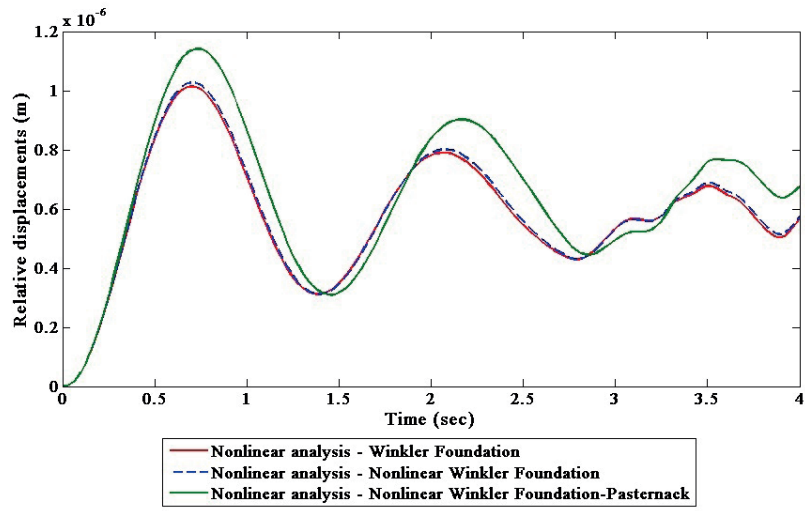

Fig. 3 Time history of the relative displacement of the pipe with shear deformation for various foundation models

Table 4 Maximum deflection of the nonlinear pipe $W_{\max }$ resting on nonlinear Winkler-Pasternack

\begin{tabular}{ccc}
\hline$W_{\max }[\mathrm{m}]$ & $\begin{array}{c}\text { Without shear } \\
\text { deformation (EBT) }\end{array}$ & $\begin{array}{c}\text { With shear deformation } \\
(\mathrm{TBT})\end{array}$ \\
\hline Without damping & $1.6715 \times 10^{-4}$ & $2.6 \times 10^{-5}$ \\
With damping & $1.502 \times 10^{-4}$ & $1.141 \times 10^{-4}$ \\
\hline
\end{tabular}

Table 3 Maximum deflection of the linear and nonlinear pipe $W_{\max }$ obtained by the all cases of analysis

\begin{tabular}{lccc}
\hline & Without shear deformation & With shear deformation & Linear \\
& Linear & Non linear & $1.1942 \times 10^{-6}$ \\
Linear Winkler & $2.273 \times 10^{-4}$ & $1.481 \times 10^{-4}$ & $1.014 \times 10^{-6}$ \\
Linear and nonlinear Winkler & $2.281 \times 10^{-4}$ & $1.490 \times 10^{-4}$ & $1.1943 \times 10^{-6}$ \\
Nonlinear Winkler -Pasternack & $2.84 \times 10^{-4}$ & $1.502 \times 10^{-4}$ & $1.1941 \times 10^{-6}$ \\
\hline
\end{tabular}


damping and shear coefficient have a great effect on the pipe response and it is interesting to note that these two parameters allow us to determine the real behavior of the pipe.

\subsection{Probabilistic analysis}

To assess the probabilistic behavior of the nonlinear pipeline resting on nonlinear Winkler-Pasternack foundation on the pipe response and to analyses the effect of the spatial variability of soil, Monte Carlo method has been used where 1000 samples have been generated by using the Matlab program. The obtained maximum deflections and bending moments of different values of the coefficients of variation $\left(C_{v}=10 \%, 30 \%, 50 \%, 70 \%\right)$ and correlation lengths $\left(L_{c}=6 \mathrm{~m}, 12 \mathrm{~m}, 24 \mathrm{~m}, 60 \mathrm{~m}\right)$ are resumed in tables. From Table 5, it can be observed that the probabilistic values of maximum displacement of different correlation length and coefficient of variation exceeds the one obtained by the deterministic analysis. It can be noted that the increase of maximum deflection value in the increase of the coefficient of variation and the correlation length until $L_{c}=24 \mathrm{~m}$. Nevertheless, when the $L_{c}$ is over $24 \mathrm{~m}$, the displacement decreases because the random soil becomes more correlated.

Finally, to demonstrate the effect of the spatial variability of the parameters of both Winkler and Pasternack foundation and for comparison reason Table 6 has been established for different values of Winkler and Pasternack correlation length $\left(L_{c}, L_{c s}\right)$ and coefficient of subgrade reaction $\left(k_{w}, k_{s}\right)$.

From Table 6, it can be observed that the displacement and the bending moment of the pipe increase with the increase in the value of the Pasternack coefficient (case D compared to B) and correlation length (case C compared to A), it observed also that the variation of correlation length of Pasternack foundation $L_{c s}$ affected more the response of the

Table 5 Comparison of the maximum deflection $W_{\max }$ and bending moment $M_{\max }$ of the pipe obtained by deterministic and probabilistic analysis

\begin{tabular}{|c|c|c|c|c|}
\hline & & & $W_{\max }[\mathrm{m}]$ & $M_{\max }[\mathrm{MN} . \mathrm{m}]$ \\
\hline \multicolumn{3}{|c|}{ Deterministic analysis } & $1.141 \times 10^{-6}$ & 884.7 \\
\hline \multirow{8}{*}{ 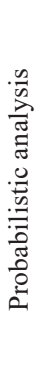 } & \multirow{5}{*}{$\begin{array}{c}C_{v} \\
\left(L_{c}=24 \mathrm{~m}\right)\end{array}$} & $10 \%$ & $1.4367 \times 10^{-6}$ & 892.08 \\
\hline & & $30 \%$ & $1.5187 \times 10^{-6}$ & 910.12 \\
\hline & & $50 \%$ & $1.9325 \times 10^{-6}$ & 948.17 \\
\hline & & $70 \%$ & $1.9500 \times 10^{-6}$ & 970.8 \\
\hline & & $6 \mathrm{~m}$ & $1.8621 \times 10^{-6}$ & 958.1 \\
\hline & \multirow{3}{*}{$\begin{array}{c}L_{c} \\
\left(C_{v}=70 \%\right)\end{array}$} & $12 \mathrm{~m}$ & $2.6643 \times 10^{-6}$ & 981,08 \\
\hline & & $24 \mathrm{~m}$ & $1.9500 \times 10^{-6}$ & 970.8 \\
\hline & & $60 \mathrm{~m}$ & $1.92536 \times 10^{-6}$ & 964.6 \\
\hline
\end{tabular}

Table 6 Maximum deflection $W_{\max }$ and bending moment $M_{\max }$ of the pipe for different Values of $k_{w}, k_{s}, L_{c}$ and $L_{c s}$

\begin{tabular}{lc}
\hline Cases & $W_{\max }[\mathrm{m}]$ \\
\hline Case A : & $M_{\max }[\mathrm{MN} . \mathrm{m}]$ \\
$k_{w}=8567 \mathrm{kN} / \mathrm{m}^{3}, L_{c}=6 \mathrm{~m}$ & $2.2001 \times 10^{-6}$ \\
$k_{s}=800 \mathrm{kN} / \mathrm{m}, L_{c s}=24 \mathrm{~m}$ & 1095.26 \\
Case B : & $1.7116 \times 10^{-6}$ \\
$k_{w}=8567 \mathrm{kN} / \mathrm{m}^{3}, L_{c}=24 \mathrm{~m}$ & 825.11 \\
$k_{s}=800 \mathrm{kN} / \mathrm{m}, L_{c s}=6 \mathrm{~m}$ & \\
Case C : & $2.7341 \times 10^{-6}$ \\
$k_{w}=8567 \mathrm{kN} / \mathrm{m}^{3}, L_{c}=6 \mathrm{~m}$ & 1361.16 \\
$k_{s}=1500 \mathrm{kN} / \mathrm{m}, L_{c s}=24 \mathrm{~m}$ & \\
Case D: & $3.8973 \times 10^{-6}$ \\
$k_{w}=8567 \mathrm{kN} / \mathrm{m}^{3}, L_{c}=24 \mathrm{~m}$ & 3533.794 \\
$\mathrm{v}=1500 \mathrm{kN} / \mathrm{m} L_{c s}=6 \mathrm{~m}$ & \\
\hline
\end{tabular}

pipe which is undergoes large deflection than the variation of correlation length of Winkler foundation $L_{c}$ (case B compared to A and case D compared to C).

\section{Conclusions}

The dynamic response of the nonlinear pipeline subjected to a distributed load and to the Loma Prieta earthquake has been studied within the framework of the Euler-Bernoulli and Timoshenko beam theories by taking into account the effect of geometric nonlinearity, shear deformation and spatial variability. The nonlinear equation of motion is determined by using the Von Kármán method and solved with using the Newmarck method combined to the Monte Carlo one. It is observed from the investigation that the spatial variability of soil properties plays very important roles in the nonlinear dynamic behavior of the pipe. Therefore, the main conclusions that can be drawn from this study are:

1. From Table 2 it can be noted that the deflection of the beam is significantly affected by the seismic parameters where the use of the dynamic analysis of is well suited for determine the real response of the pipe.

2. The response of the pipe is strongly influenced by the effect of the shear deformation which has an important role on the determination of the deflections of the beam. Moreover, the discrepancy between the results of the linear and nonlinear analysis of the pipe resting on Winkler foundation and on WinklerPasternack foundation is remarkable.

3. The damping coefficient is an important parameter, in fact it reduces the deflection of the pipe and it is important to take it into account in order to optimize results and to provide a more realistic behavior of the pipe. 
4. The nonlinear parameters of the foundation have also a great influence on the behavior of the pipe. In fact, the coefficient of variation $C_{v}$ and the correlation lengths have a significant effect on the nonlinear response of the pipe. Namely, increase in the $C_{v}$ of variation and correlation lengths $\left(L_{c}, L_{c s}\right)$ cause increase in the maximum deflection and bending moment. Therefore, a random soil with higher values of coefficient of variation of different type foundations enable us to obtain a more realistic behavior of a beam.

\section{References}

[1] Winkler, E. "Die Lehre von der Elasticitaet und Festigkeit" (The theory of elasticity and strength), Dominicus, Prague, Czech Republic, 1867. (in German)

[2] Vesic, A. B. "Bending of beams resting on isotropic elastic solid", Journal of the Engineering Mechanics Division, 87(2), pp. 35-54, 1961.

[3] Vesic, A. B. "Beams on Elastic Subgrade and Winkler's Hypothesis", In: Proceedings of the 5th International Conference on Soil Mechanics and Foundation Engineering, Paris, France, 1963, pp. 845-850.

[4] Kerr, A. D. "Elastic and Viscoelastic Foundation Models", Journal of Applied Mechanics, 31(3), pp. 491-498, 1964.

https://doi.org/10.1115/1.3629667

[5] Kerr, A. D. "A study of a new foundation model", Acta Mechanica, 1, pp. 135-147, 1965.

https://doi.org/10.1007/BF01174308

[6] Zhaohua, F., Cook, D. R. "Beam Elements on Two-Parameter Elastic Foundation", Journal of Engineering Mechanics, 109(6), pp. 1390-1402, 1983.

[7] Wang, T. M., Gagnon, L. W. "Vibrations of continuous Timoshenko beams on Winkler-Pasternak foundations", Journal of Sound and Vibration, 59(2), pp. 211-220, 1978.

https://doi.org/10.1016/0022-460X(78)90501-1

[8] Hindy, A., Novak, M. "Earthquake response of underground pipelines", Earthquake Engineering Structural Dynamics, 7(5), pp. 451476, 1979.

https://doi.org/10.1002/eqe.4290070506

[9] Selvadurai, A. P. S. "Soil-pipe interaction during ground movement", In: Bennett, F. L., Machemehl, J. L. (eds.) Proceedings of the Conference Arctic '85; Civil Engineering in the Artic offshore, San Francisco, CA, USA, 1985, pp. 763-773.

[10] Pellicano, F., Mastroddi, F. "Nonlinear Dynamics of a Beam on Elastic Foundation", Nonlinear Dynamics, 14, pp. 335-355, 1997. https://doi.org/10.1023/A:1008297721253

[11] Matsubara, K., Hoshiya, M. "Soil Spring Constants of Buried Pipelines for Seismic Design", Journal of Engineering Mechanics, 126(1), pp. 76-83, 2000. https://doi.org/10.1061/(ASCE)0733-9399(2000)126:1(76)

[12] Hosseini Kordkheili, S. A., Bahai, H., Mirtaheri, M. "An updated Lagrangian finite element formulation for large displacement dynamic analysis of three-dimensional flexible riser structures", Ocean Engineering, 38(5-6), pp. 793-803, 2011. https://doi.org/10.1016/j.oceaneng.2011.02.001
5. The developed model yield very good predictions of the dynamic response of the nonlinear pipe resting on nonlinear soil where the Timoshenko beam theory must be used instead of Euler-Bernoulli beam theory and the shear layer effect hasn't to be neglected because of the effect of the shear stresses on the deformation.

[13] Bathe, K.-J. "Finite element procedures in engineering analysis", Prentice Hall, Englewood Cliffs, NJ, USA, 1982.

[14] Sun, L. "A Closed-Form Solution of a Bernoulli-Euler Beam On a Viscoelastic Foundation Under Harmonic Line Loads", Journal of Sound and Vibration, 242(4), pp. 619-627, 2001. https://doi.org/10.1006/jsvi.2000.3376

[15] Chang, S.-Y. "Studies of Newmark method for solving nonlinear systems (I) basic analysis", Journal of the Chinese Institute of Engineers, 27(5), pp. 651-662, 2004. https://doi.org/10.1080/02533839.2004.9670913

[16] Çalım, F. F. "Dynamic analysis of beams on viscoelastic foundation". European Journal of Mechanics - A/Solids, 28(3), pp. 469-476, 2009. https://doi.org/10.1016/j.euromechsol.2008.08.001

[17] Katifeoglou, S. A., Chatjigeorgiou, I. K. "Dynamic interaction of catenary risers with the seafloor", Applied Ocean Research, 38, pp. $1-15,2012$.

https://doi.org/10.1016/j.apor.2012.06.001

[18] Sapountzakis, E. J., Kampitisis, A. E. "Nonlinear Dynamic Analysis of Shear Deformable Beam-Columns on Nonlinear Three-Parameter Viscoelastic Foundation. I: Theory and Numerical Implementation", Journal of Engineering Mechanics, 139(7), pp. 886-896, 2013. https://doi.org/10.1061/(ASCE)EM.1943-7889.0000369

[19] Grigoriu, M., Khater, M., O'Rourke ,T. "Stochastic Beams on Elastic Foundation", Proceedings of the Symposium of ASCE Convention, Denver, CO, USA, 1985, pp. 96-106.

[20] Griffiths, D. V., Paiboon, J., Huang, J., Fenton, G. A. "Numerical analysis of beams on random elastic foundations", In: Proceedings of the CIMENICS 2008, IX. International Congress on Numerical Methods in Engineering and Applied Sciences, Caracas, Venezuela, 2008, pp. 19-25.

[21] Rackwitz, R. "Reviewing probabilistic soil modeling", Computers and Geotechnics, 26(3-4), pp. 199-223, 2000. https://doi.org/10.1016/S0266-352X(99)00039-7

[22] Elachachi, S. M., Breysse, D., Houy, L. "Longitudinal variability of soils and structural response of sewer networks", Computers and Geotechnics, 31(8), pp. 625-641, 2004. https://doi.org/10.1016/j.compgeo.2004.10.003

[23] Elachachi, S. M., Breysse, D., Benzeguir, H. "Soil Spatial Variability and Structural Reliability of Buried Networks Subjected to Earthquakes", In: Papadrakakis, M., Stefanou, G., Papadopoulos, V. (eds.) Computational Methods in Applied Sciences, Springer, Dordrecht, Netherlands 2011, pp. 111-27. https://doi.org/10.1007/978-90-481-9987-7_6 
[24] Singh, B. N., Lal, A., Kumar, R. "Nonlinear bending response of laminated composite plates on nonlinear elastic foundation with uncertain system properties", Engineering Structures, 30(4), pp. 1101-1112, 2008.

https://doi.org/10.1016/j.engstruct.2007.07.007

[25] Kazi Tani, N., Nedjar, D., Hamane, M. "Non-linear analysis of the behaviour of buried structures in random media", European Journal of Environmental and Civil Engineering, 17(9), pp. 791-801, 2013. https://doi.org/10.1080/19648189.2013.822426

[26] Seguini, M., Nedjar, D. "Modelling of soil-structure interaction behaviour: geometric nonlinearity of buried structures combined to spatial variability of soil", European Journal of Environmental and Civil Engineering, 21(10), pp. 1217-1236, 2016. https://doi.org/10.1080/19648189.2016.1153525

[27] Seguini, M., Nedjar, D. "Nonlinear finite element modeling of deep beam resting on linear and nonlinear random soil", International Journal of Geological and Environmental Engineering, 10(2), pp. 121-128, 2016. https://doi.org/10.5281/zenodo.1339099

[28] Seguini, M., Nedjar, D. "Nonlinear Analysis of Deep Beam Resting on Linear and Nonlinear Random Soil", Arabian Journal for Science and Engineering, 42, pp. 3875-3893, 2017. https://doi.org/10.1007/s13369-017-2449-7

[29] Seguini, M., Nedjar, D. "Stochastic Finite Element Analysis of Nonlinear Beam on Winkler-Pasternack Foundation", In: Proceedings of the 1st International Conference on Numerical Modelling in Engineering, Ghent, Belgium, 2018, pp. 14-29. https://doi.org/10.1007/978-981-13-2405-5_2

[30] Nedjar, D., Bensafi, M., Elachachi, S. M., Hamane, M., Breysse, D. "Buried pipe response under seismic solicitation with soil-pipe interaction", In: Mestat, A. (ed.) Numerical Methods in Geotechnical Eengineering Conference, Paris, France, 2002, pp. 1047-1053.
[31] Nedjar, D., Hamane, M., Bensafi, M., Elachachi, S. M., Breysse, D. "Seismic response analysis of pipes by a probabilistic approach", Soil Dynamics and Earthquake Engineering, 27(2), pp. 111-115, 2007. https://doi.org/10.1016/j.soildyn.2006.06.001

[32] Zerva, A. "Effect of spatial variability and propagation of seismic ground motions on the response of multiply supported structures", In: Probabilistic Engineering Mechanics, 6(3-4), pp. 212-221, 1991. https://doi.org/10.1016/0266-8920(91)90012-S

[33] Kholmyansky, M. L. "Dynamic Soil-Structure Interaction Considering Random Soil roperties", In: The 12th International Conference of International Association for Computer Methods and Advances in Geomechanics (IACMAG), Goa, India, 2008, pp. 2704-2711.

[34] Na, U. J., Chaudhuri, S. R., Shinozuka, M. "Effects of spatial variation of soil properties on seismic performance of port structures", Soil Dynamics and Earthquake Engineering, 29(3), pp. 537-545, 2009.

https://doi.org/10.1016/j.soildyn.2008.06.002

[35] Reddy, J. N. "An Introduction to Nonlinear Finite Element Analysis", Oxford University Press, Oxford, UK, 2004. https//doi.org/10.1093/acprof:oso/9780198525295.001.0001

[36] Cowper, G. R. "The Shear Coefficient in Timoshenko's Beam Theory", Journal of Applied Mechanics, 33(2), pp. 335-340, 1966. https://doi.org/10.1115/1.3625046

[37] Vanmarcke, E. "Random Fields: Analysis and Synthesis", MIT Press, Cambridge, UK, 1983.

[38] Fenton, G. A., Vanmarcke, E. H. "Simulation of Random Fields via Local Average Subdivision", Journal of Engineering Mechanics, 116(8), pp. 733-1749, 1990. https://doi.org/10.1061/(ASCE)0733-9399(1990)116:8(1733) 